\title{
Effect of peppermint (Mentha piperita) essential oil on in vitro gas production parameters of lucerne hay and cottonseed hulls
}

\author{
E. Jani ${ }^{1}$, M. Danesh Mesgaran ${ }^{2}$, A.R. Vakili ${ }^{2}$, A. Soleimani ${ }^{1}$, H. Jahani-Azizabadi ${ }^{2}$
}

${ }^{1}$ Islamic Azad University of Kashmar, Kashmar, Khorasan, Islamic Republic of Iran

${ }^{2}$ Department of Animal Science (Excellence Center for Animal Science), Faculty of Agriculture, Ferdowsi University of Mashhad, Mashhad, Khorasan Razavi, Islamic Republic of Iran

Email: elhamjani62@yahoo.com

Introduction In ruminants, ionophores have been used to enhance ruminal fermentation. However, because of human health concerns, plant extracts and essential oils are used as alternative natural feed additives in replacement of ionopheres (Garcia-Gonzalez et al., 2008). The amount of gas produced from a feed is used as an index of its fermentability potential (Menke and Steingass, 1988). The aim of the present study was to evaluate the effect of peppermint (Mentha piperita) essential oil on the fermentation potential of lucerne hay (LH) and cottonseed hulls $(\mathrm{CH})$.

Material and methods Peppermint essential oil (PE) is produced by heating peppermint leaves and stems to $100{ }^{\circ} \mathrm{C}$ for 24 $\mathrm{h}$ and collecting the vapour as a distillate. Samples of $\mathrm{LH}$ and $\mathrm{CH}$ were ground through a $2 \mathrm{~mm}$ screen and dried in an oven at $66^{\circ} \mathrm{C}$ for $48 \mathrm{~h}$. Samples were LH, CH and both feed samples plus PE (14 and $40 \mu \mathrm{l} / \mathrm{g} \mathrm{DM}$ ) using a $2 \times 3$ factorial design. In vitro gas production parameters of the samples were determined using the Menke and Steingass (1988) procedure. Approximately $0.3 \mathrm{~g}$ of sample $(\mathrm{n}=4)$ was placed in a $100 \mathrm{ml}$ glass syringe containing $40 \mathrm{ml}$ of buffered rumen fluid (ratio of buffer to rumen fluid was 2: 1). Rumen fluid was obtained from two rumen cannulated sheep (45.5 $\pm 2 \mathrm{~kg}$, body weight) before the morning feed and immediately strained through four layers of cheesecloth. Animals were fed with $1.5 \mathrm{~kg} \mathrm{DM}$ lucerne hay and $0.4 \mathrm{~kg}$ DM concentrates $(165 \mathrm{~g} \mathrm{CP} / \mathrm{kg} \mathrm{DM})$ per head per day. Syringes were incubated at $39{ }^{\circ} \mathrm{C}$ and the volume of gas produced was recorded at 2, 4, 8, 12, 24, 36, 48, 72 and $96 \mathrm{~h}$. Statistical analysis was conducted using SAS (1999) procedure. The gas production data were fitted to an exponential equation of $P=b\left(1-e^{-c t}\right)$, where $b$ is the volume of gas produced, $c$ is the fractional rate constant of gas production $(/ \mathrm{h}), t$ is the incubation time $(\mathrm{h})$ and $P$ is the volume of gas produced at time $t$.

Results The effect of PE on gas production parameters of LH and CH are shown in Table 1. Supplementation of both LH and $\mathrm{CH}$ with $\mathrm{PE}$ reduced the volume of gas produced $(\mathrm{P}<0.05)$. However, $\mathrm{PE}$ had no significant effect on the fractional rate $(c)$ of gas production [except in LH supplemented with $\mathrm{PE}$ as $40 \mu \mathrm{l} / \mathrm{g} \mathrm{DM}$, in which $c$ was increased $(\mathrm{P}<0.05)]$.

Table 1 Effect of peppermint (Mentha piperita) essential oil on gas production parameters of lucerne hay and cottonseed hulls (Mean \pm s.e.m)

\begin{tabular}{|c|c|c|c|c|c|c|c|c|}
\hline & \multicolumn{6}{|c|}{ Feed Samples } & & \\
\hline & \multicolumn{3}{|c|}{ Lucerne hay } & \multicolumn{3}{|c|}{ Cottonseed hulls } & & \\
\hline & \multicolumn{3}{|c|}{ Level of PE $(\mu \mathrm{l} / \mathrm{g} \mathrm{DM})$} & \multicolumn{3}{|c|}{ Level of PE $(\mu 1 / \mathrm{g}$ DM $)$} & & \\
\hline Gas production parameters & - & 14 & 40 & - & 14 & 40 & s.e.m. & $P$ value \\
\hline$b$ & $72.000^{\mathrm{a}}$ & $61.040^{\mathrm{b}}$ & $45.300^{\mathrm{c}}$ & $99.000^{\mathrm{d}}$ & $74.540^{\mathrm{a}}$ & $21.800^{\mathrm{e}}$ & 3.450 & $<0.05$ \\
\hline$c$ & $0.070^{\mathrm{a}}$ & $0.067^{\mathrm{a}}$ & $0.078^{\mathrm{b}}$ & $0.011^{\mathrm{c}}$ & $0.013^{\mathrm{c}}$ & $0.012^{\mathrm{c}}$ & 0.002 & $<0.05$ \\
\hline
\end{tabular}

a, b,c, d, e: Means within each feed sample with a different letters in each row are significant

Conclusions The unique finding of the present study is the reduction of the gas produced from quickly and slowly degradable fractions when PE was applied in both $\mathrm{LH}$ and $\mathrm{CH}$. However, the rate constant of gas produced from $\mathrm{CH}$ was not influenced by the adding of PE. Therefore, it was concluded that PE had a potential to reduce the fermentability of LH when applied as $40 \mu \mathrm{l} / \mathrm{g} \mathrm{DM}$.

Acknowledgements The authors gratefully acknowledge funding from Excellence Centre for Animal Science, Ferdowsi University of Mashhad.

\section{References}

Garcia-Gonzalez, R. Lopez, S. Fernandez, M. Bodas, R. and Gonzalez, J.S. 2008. Animal Feed Science and Technology 147, 36-52.

Menke, K.H. and Steingass, H. 1988. Animal Research Development. 28, 7-55.

SAS. Users Guide, Statistics. 1999. Version 8.2. SAS Institute, Inc., Cary, NC, USA. 